\title{
Early-onset anorexia nervosa in girls with Asperger syndrome
}

\author{
This article was published in the following Dove Press journal: \\ Neuropsychiatric Disease and Treatment \\ 2 July 2015 \\ Number of times this article has been viewed
}

\section{Iva Dudova \\ Jana Kocourkova \\ Jiri Koutek}

Department of Child Psychiatry, Charles University Second Faculty of Medicine and University Hospital Motol, Prague, Czech Republic
Correspondence: Iva Dudova Department of Child Psychiatry, Charles University Second Faculty of Medicine and University Hospital Motol, V Uvalu 84, Prague 15006, Czech Republic

Tel +420224433458

Fax +420224433420

Email iva.dudova@lfmotol.cuni.cz

\begin{abstract}
Eating disorders frequently occur in conjunction with autism spectrum disorders, posing diagnostic and therapeutic difficulties. The comorbidity of anorexia nervosa and Asperger syndrome is a significant clinical complication and has been associated with a poorer prognosis. The authors are presenting the cases of an eleven-year-old girl and a five-and-a-half-year-old girl with comorbid eating disorders and Asperger syndrome.
\end{abstract}

Keywords: eating disorders, early-onset anorexia nervosa, autism spectrum disorders, Asperger syndrome, diagnostics, therapy

\section{Introduction}

Eating disorders were described in the early descriptions of patients with Asperger syndrome. ${ }^{1}$ Asperger syndrome is a serious and chronic neurodevelopmental disorder, which is presently defined by social deficits, restricted interests, and relative preservation of language and cognitive ability. ${ }^{2}$ In Diagnostic and Statistical Manual of Mental Disorders (DSM)-IV, the syndrome was considered to be separate, but it fell under the broader category of pervasive developmental disorders. In DSM-V, Asperger syndrome falls into the autism spectrum disorder (ASD) diagnostic category. ASD is a disorder with persistent deficits in social interaction and communication skills, accompanied by restricted, repetitive patterns of behavior, interests, or activities and by atypical sensory reactivity. ${ }^{3}$ We know nowadays that eating disorders take various forms and are often presented in ASD, complicating both diagnosis and therapy. Rastam $^{4}$ offered a summary of these disorders stating that abnormal eating behaviors are overrepresented in ASD, including food refusal, pica, rumination, and selective eating. She considers the connection between anorexia nervosa (AN) and ASD as interesting and states that Asperger syndrome is sometimes not recognized in female teenagers with eating disorders. There is a risk that autistic traits in girls with AN are overlooked, which may lead to a simplification in the diagnostic consideration and therapeutic procedures. A contemporary review publication has explained that ASDs are overrepresented in individuals who develop AN and also that ASDs are common in chronic cases of AN. ${ }^{5}$ This comorbidity has been associated with a poorer prognosis. ${ }^{6}$ The research by Baron-Cohen et al ${ }^{7}$ confirms that girls with AN have elevated autistic traits. The authors point out that clinicians should consider whether a focus on autistic traits might be helpful in the assessment and treatment of anorexia.

AN is a typical disorder in adolescent girls and young women. Early-onset AN (in children under the age of 12 years) represents approximately $5 \%$ of all cases. It is a serious disorder jeopardizing the development of children in the somatic and psychosocial areas, and it seems that its incidence is growing. ${ }^{8}$ In individual research 
groups where early-onset is indicated, there is not always agreement as to the precise age definition of "early-onset"; some authors describe premenarcheal girls, others refer to the age between 8 and 14 years. ${ }^{9}$

Both AN and early-onset eating disorders include syndromes of food avoidance emotional disorder and selective eating. Specific psychopathology of early-onset AN is very similar to the disorder onset in adolescence..$^{10} \mathrm{An}$ extensive study by Halmi et al ${ }^{11}$ suggests that the predominant feature that precedes all AN subtypes is global childhood rigidity, which is a trait that leads to resistance to changes. Pooni et al ${ }^{12}$ found a higher incidence of autistic traits in individuals with early-onset eating disorders ( $8-16$ years) compared with typically developing peers, namely, repetitive and stereotyped behaviors, and also trends toward higher levels of autistic social impairment. Coombs et al ${ }^{13}$ looked into the relationship between eating disorder psychopathology and autistic symptomatology in a non-clinical sample of school children aged 11-14 years with no recorded psychiatric diagnoses, and found a significant relationship between the level of eating disorder symptomatology and ASD symptomatology. According to Karlsson et a $1^{14}$ eating disorders are common in ASD but are often being overlooked. They developed a psychometrically and statistically valid SWedish Eating Assessment for Autism spectrum disorders questionnaire detecting eating disorders, which has been designed for individuals with ASD aged 15-25 years with normal intelligence; in younger patients, clinical assessment has to suffice at the moment.

\section{Clinical implication}

The question of relationship, similarity, and connection between ASD and AN has diagnostic and therapeutic importance in clinical practice. Apart from the diagnosis of clinical AN syndrome, it is necessary to assess the development of cognitive and psychosocial traits of a child, including the possibility of identifying ASD or prominent autistic traits. Equally, in ASD patients it is important to consider the occurrence of eating disorders associated with cognitive and psychosocial peculiarities. It is crucial to identify the subgroup of AN cases with concomitant ASD. The therapeutic basis must respect these development peculiarities and make them part of the therapeutic program.

The results imply that young people with AN would benefit from a treatment approach tailored to the needs of individuals on the autism spectrum. ${ }^{15}$ Kerbeshian and Burd ${ }^{16}$ have shown an inspiring approach on the case history of a 12-year-old girl with high-functional autism and partial AN.
They have demonstrated that the treatment approaches used with individuals with neuropsychiatric developmental disorders might be effective in higher functioning individuals with eating disorders. Therapeutic implications emphasize the need to improve cognitive and social functions, ${ }^{17}$ deficits in the field of mentalization, ${ }^{18}$ and the importance of focusing on working with the family. ${ }^{19}$

\section{Case history I}

A girl aged 10 years and 9 months was admitted to a children's psychiatric clinic with an eating disorder and an underlying diagnosis of Asperger syndrome. The patient's parents had degrees from technical universities and were healthy. The patient's sister, a grammar school student, was 2 years older and had Asperger syndrome. The psychomotor development in the patient was normal. She began to form individual words at 8 months and sentences from 24 months, but did not speak much until the age of 4 years. She began to speak fluently at the age of 4 years. At the age of 4.5 years, she was able to read and write and made her own comic books. She managed to fit into a small group of children in kindergarten. In the third year of school, she joined a partly new group in a language class and got a new class teacher. She began to dislike going to school; she had mood swings, sometimes there were suicidal proclamations; and she withdrew from her peers. At the end of the school year, she did not manage a school trip lasting several days, she ended up disorientated, and she ran away from the teachers several times. She said that she had been confused because of the change in the daily routine that she was used to at school. The diagnosis of Asperger syndrome was considered for the first time at this point, yet the ADHD diagnosis was erroneously established, and the girl was medicated with atomoxetine, $40 \mathrm{mg}$ per day. When on the medication, she lost appetite and began to reduce the food intake. She had never been a great eater, but until the age of 9 years the parents never noticed any eating problems. The problems persisted after discontinuation of atomoxetine due to lack of effect. She ate small portions of food at precisely the same times daily. In the year leading up to the children's psychiatric clinic admission, she grew $12 \mathrm{~cm}$ and her weight reduced by $5 \mathrm{~kg}$.

On admission to the children's psychiatric clinic, Asperger syndrome was suspected. Most of the time, the patient used a pseudo-adult language in conversation and spoke in a high-pitched voice with unnatural intonation. She thought she was slender and liked being so. She said on several occasions that she wanted to be the skinniest girl in the world. At other times, she expressed her wish to be a model, fashion designer, and world-famous painter. The eating regimen at the ward was 
first accompanied by high tension, even affective seizures; she refused food, and behaved in a bizarre way (concealed food in clothes, escaped, cried loudly, proclaimed suicide). After several days of adapting to the regimen, she began to accept food, and the diet. The Asperger syndrome diagnosis was confirmed using the Autism Diagnostic Observation Schedule (ADOS) ${ }^{20}$ testing method and following an interpretation of the psychological examination. The girl had a prominently impaired perception of her own body, little interest in social contact, egocentric perception, and infantile expression. She would escape in an imaginary world in which she was a famous and respected artist. Her introspection was minimal; affective seizures grew in number with her growing weight. During the hospitalization, her weight increased by $8 \mathrm{~kg}$ following a plan, and she kept her eating regimen even during visits home. She was released after 8 weeks with the diagnoses of Asperger syndrome and AN.

\section{Case history 2}

A patient aged 5 years 6 months came for her first outpatient psychiatric examination. The parents requested consultation because of some peculiarities in their daughter's behavior and habits, emphasizing on eating problems. For about 6 months, the girl made a point of emphasizing her hair, fashion, and slenderness. She expressed her opinion that being fat meant being ugly and mean, and sometimes made tactless remarks about people around her. She absolutely refused to accept that somebody could be fat and happy. She insisted on specific odd arrangements when eating; she had to sit at her own place, have her own dishes, and minimized the food and drink she took. She said repeatedly that she did not want to be fat and old, and she kept asking her parents strange questions on this topic again and again.

In the patient's history, there was suspicion of Asperger syndrome. According to the parents, she did not have any capability of empathy, never asked personal questions, considered mainly her own self, and was a "great egoist". In social contacts, she was aloof and passive in relation to peers and adults; she only critically commented on what was happening around her without becoming much involved. There were great problems in adapting to changes (changes in routes, clothes, daily routine) accompanied by negative reactions or even affective seizures with verbal and brachial aggression. Her playing had elements of stereotypes; there were finger mannerisms. In conversation, she showed signs of impaired communication and social interaction. Using the ADOS testing method, ASD was determined and the patient was diagnosed with Asperger syndrome. Concerning her eating disorder (minimizing food intake, rigid eating habits, specific arrangements when eating), the parents were recommended to approach this as a symptom of the ASD diagnosis.

\section{Discussion}

The occurrence of AN in Asperger syndrome has been described in literature. ${ }^{5}$ Good understanding of the connection between these two disorders is crucial both for diagnosis and treatment. The therapeutic points of departure must respect the individual composition of symptoms and their mutual links. The picture of AN is always critically influenced by the presence of a pervasive developmental disorder. The clinical guidance of patients with such comorbidities is always more demanding and requires experience with both diagnoses. The patients' case histories illustrate the issues and make it possible to share the clinical experience. Important issues are raised in the understanding of the comorbidity of these disorders and the implications for treatment.

In 1985, Gillberg ${ }^{21}$ was the first to describe cases where a relationship between children's autism and AN was established (four cases of autistic boys whose close relatives suffered from AN). The first clear clinical case report was submitted by Rothery and Garden ${ }^{22}$ who described the case of a 16-year-old girl with AN who was previously diagnosed as having infantile autism. This case illustrates that $\mathrm{AN}$ does occur in adolescents with autism and that it is important it is diagnosed, so that appropriate treatment can be given.

Similarly, Fisman et $\mathrm{al}^{23}$ described the development of $\mathrm{AN}$ in a high-functioning autistic adolescent 13-year-old girl. Autism was diagnosed when the patient was 4 years old, and a change in eating habits started approximately a year prior to the admission. Hospitalization was suggested because of continued weight loss accompanied by increasing refusal to eat and the failure to disengage parents from the patient's eating and weight preoccupation. A structured behavioral approach was implemented, and risperidone was prescribed. This case study illustrates, besides a clear comorbidity of both diagnoses, an example where a combined psychotherapeutic and pharmacological strategy resulted in good improvement.

Kerbeshian and Burd ${ }^{16}$ presented a case report of multiple comorbidities in a 12-year-old girl with high-functioning autistic disorder who developed Tourette syndrome, obsessive-compulsive disorder, and AN. The authors proposed the concept that $\mathrm{AN}$ is a neuropsychiatric developmental 
disorder. Cognitive behavioral psychotherapy has long been utilized with benefit in treating these disorders.

Our cases document the difficulty in diagnosing and treating patients with concurrent eating and pervasive developmental disorders. In our first case history of a nearly 11-year-old girl, there was a clear comorbidity of early-onset AN and Asperger syndrome; the diagnostic criteria for both the disorders were fulfilled. Compared with patients of similar age, the signs of AN (such as the disorder of the body schema, minimizing food intake, lack of introspection) were more persistent and difficult to influence with the therapeutic procedures commonly applied in cases of eating disorders. The persistence and rigidity so typical of Asperger syndrome hindered the work with the patient both in the therapeutic regimen and in the individual, group, and family therapy. The girl needed longer than the usual to adapt to the therapeutic regimen and to accept it, then she rigidly insisted on keeping it, both for herself and for her fellow patients with eating disorders. The success of the therapy depended on the selection of a suitable motivating approach to the patient taking into consideration her traits stemming from the underlying Asperger syndrome diagnosis.

In our second case history, the eating problem was rather more part of the core symptoms of Asperger syndrome, even though the eating disorder was the original reason for the psychiatric assessment. The manipulation around food could be interpreted as a communication means in a child with impaired social and communication abilities. The therapy aimed mainly at the newly established Asperger syndrome diagnosis. Only if this therapy fails would we recommend a more targeted approach to the eating disorder. It is important that we notice these anorectic traits in patients, especially at a young age, which is not typical for the incidence of AN.

\section{Conclusion}

It follows from literature and our clinical experience that the comorbidity of eating disorders and ASD is not unusual. Our statement is based on the detailed description of two clinical cases of girls with Asperger syndrome and symptoms of AN. It is necessary to distinguish which symptoms are part of the underlying diagnosis and which are distinctive comorbid symptoms. The therapy must be adapted accordingly. Both diagnosis and therapy should be performed by experts experienced in working with patients with both the diagnoses. We believe that the most efficient in infancy and adolescence is the combined therapeutic strategy, which involves a structured behavioral approach as well as psychotherapy, pharmacotherapy, and family therapy.

\section{Acknowledgment}

This paper was written within the Programme for the Development of Fields of Study at Charles University (P07 Psychosocial Aspects of the Quality of Human Life) and was supported by the Ministry of Health, Czech Republic. Conceptual development of research: University Hospital Motol, Prague, Czech Republic 00064203.

\section{Disclosure}

The authors report no conflicts of interest in this work.

\section{References}

1. Asperger H. Die "autischisten psychopathen" in kindesalter [Autistic psychopaths in childhood]. Arch PsychiatrNervenkr. 1944;117: 76-136. German.

2. Klin A, Volkmar FR, Sparrow SS, editors. Asperger Syndrome. New York: The Guilford Press; 2000.

3. American Psychiatric Association. Diagnostic and Statistical Manual of Mental Disorders. 5th ed. Arlington (VA): American Psychiatric Publishing; 2013.

4. Rastam M. Eating disturbances in autism spectrum disorders with focus on adolescent and adult years. Clin Neuropsychiatry. 2008;5(1): $31-42$.

5. Rastam M, Wentz E. ASD, eating problems, and overlap with anorexia and bulimia nervosa. In: Patel VB, Preedy VR, Martin CR, editors. Comprehensive Guide to Autism. New York: Springer; 2014:2015-2034.

6. Rhind C, Bonfioli B, Hibbs R, et al. An examination of autism spectrum traits in adolescents with anorexia nervosa and their parents. Mol Autism. 2014;5:56.

7. Baron-Cohen S, Jaffa T, Davies S, et al. Do girls with anorexia nervosa have elevated autistic traits? Mol Autism. 2013;4:24.

8. Lask B, Waugh R, Gordon I. Childhood-onset anorexia nervosa is a serious illness. Adolescent nutritional disorders: prevention and treatment. Ann N Y Acad Sci. 1997;17:120-126.

9. Lask B, Bryant-Waugh R. Early-onset anorexia nervosa and related eating disorders. $J$ Child Psychol Psychiatry. 1992;33(1): 281-300.

10. Cooper PJ, Watkins B, Bryant-Waugh R, Lask B. The nosological status of early onset anorexia nervosa. Psychol Med. 2002;32(5): 873-880.

11. Halmi KA, Bellace D, Berthold S, et al. An examination of early childhood perfectionism across anorexia nervosa subtypes. Int J Eat Disord. 2012;45(6):800-807.

12. Pooni J, Ninteman A, Bryant-Waugh R, et al. Investigating autism spectrum disorder and autistic traits in early onset eating disorder. Int $J$ Eat Disord. 2012;45(4):583-591.

13. Coombs E, Brosnan M, Bryant-Waugh R, Skevington SM. An investigation into the relationship between eating disorder psychopathology and autistic symptomatology in non-clinical sample. Br J Clin Psychol. 2011;50(3):326-338.

14. Karlsson L, Rastam M, Wentz E. The Swedish Eating Assessment for Autism spectrum disorders (SWEAA) - Validation of a self-report questionnaire targeting eating disturbances within the autism spectrum. Res Dev Disabil. 2013;34(7):2224-2233.

15. Nilsson EW, Gillberg CH, Gillberg C, Rastam M. Ten-year follow-up of adolescent-onset anorexia nervosa: personality disorders. $J$ Am Acad Child Adolesc Psychiatry. 1999;38:1389-1395.

16. Kerbeshian J, Burd L. Is anorexia nervosa a neuropsychiatric developmental disorder? World J Biol Psychiatry. 2009;10:648-657.

17. Oldershaw A, Treasure J, Hambrook D, et al. Is anorexia nervosa a version of autism spectrum disorders? Eur Eat Disorders Rev. 2011;19: 462-474. 
18. Skarderud F. Eating one's words: part III. Mentalization-based psychotherapy for anorexia nervosa - an outline for a treatment and training manual. Eur Eat Disorders Rev. 2007;15:323-339.

19. Treasure J, Russell G. The case for early intervention in anorexia nervosa: theoretical exploration of maintaining factors. Br J Psychiatry. 2011;199:5-7.

20. Lord C, Risi S, Lambrecht L, et al. The Autism Diagnostic Observation Schedule-Generic: a standard measure of social and communication deficits associated with the spectrum of autism. J Autism Dev Disord. 2000;30:205-223.
21. Gillberg C. Autism and anorexia nervosa: related conditions? Nordisk Psykiatrisk Tidskrift. 1985;39:307-312.

22. Rothery DJ, Garden GM. Anorexia nervosa and infantile autism. Br J Psychiatry. 1988;153:714.

23. Fisman S, Steele M, Short J, et al. Case study: anorexia nervosa and autistic disorder in an adolescent girl. J Am Acad Child Adolesc Psychiatry. 1996;35(7):937-940.

\section{Publish your work in this journal}

Neuropsychiatric Disease and Treatment is an international, peerreviewed journal of clinical therapeutics and pharmacology focusing on concise rapid reporting of clinical or pre-clinical studies on a range of neuropsychiatric and neurological disorders. This journal is indexed on PubMed Central, the 'PsycINFO' database and CAS, and is the official journal of The International Neuropsychiatric Association (INA). The manuscript management system is completely online and includes a very quick and fair peer-review system, which is all easy to use. Visit http://www.dovepress.com/testimonials.php to read real quotes from published authors.

Submit your manuscript here: http://www.dovepress.com/neuropsychiatric-disease-and-treatment-journal 